\title{
Importance of Hpv Positivity in Squamous Cell Head and Neck Cancer
}

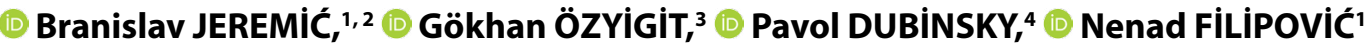 \\ 'Department of Oncology, Bio IRC, R\&D Center for Biomedical Research, Kragujevac-Serbia \\ ${ }^{2}$ Department of Radiation Oncology, Research Institute of Clinical Medicine, Tbilisi-Georgia \\ ${ }^{3}$ Department of Radiation Oncology, Haceteppe University, Ankara-Turkey \\ ${ }^{4}$ Department of Radiation Oncology, East Slovakia Institute of Oncology, Kosice-Slovakya
}

\begin{abstract}
SUMMARY
The last three decades provided new insights into the discovery of the entity related to several strains of human papillomavirus (HPV). The viral cause of HPV, primarily found in the oropharynx, was officially recognized by the World Health Organization in 2007. While epidemiologic studies around the world showed an increased incidence of HPV-related heads and neck cancers (HNC), they also established a photo robot of a typical person suffering from HPV: younger white man, suffering from a nonkeratinized type of squamous cell carcinoma, rarely being seen as heavy smoker and/or drinker. The patient with specific sexual behavior pattern usually carried low $\mathrm{T}$ and high $\mathrm{N}$ burden, HPV16 being detected in the vast majority of HPV+ tumors, mostly in the oropharynx. It was also recognized that HPV-related cancers seem to have a better prognosis than their HPV-unrelated counterparts. This observation served as an important starting point for clinical studies aiming first to identify different risk groups and then to design various de-intensification treatment strategies which aimed to maintain high success rate with e.g. lower radiotherapy and/or chemotherapy doses while decreasing side effects such deintensified treatment strategies should bring. This review summarizes the most important aspects of HPV-related HNC.
\end{abstract}

Keywords: Chemotherapy; HPV; radiotherapy.

Copyright $\odot$ 2019, Turkish Society for Radiation Oncology

\section{Introduction}

The annual incidence of head and neck cancers (HNC) worldwide is rising, with more than 600.000 cases resulting in more than 300.000 deaths each year.[1,2,3] The last three decades brought important discoveries which facilitated the identification of a distinct entity within $\mathrm{H} \& \mathrm{~N}$ sites, primarily in the oropharynx. This entity is related to several strains of human papillomavirus (HPV+) [4], and the viral cause of this disease was officially recognized by the World Health Orga- nization in 2007.[5] It seemed to have a significantly better prognosis than observed in those not associated with HPV infection but associated with tobacco and alcohol (HPV-). A change in survival in the most recent decade for oropharyngeal cancers (OPC) with unknown HPV status was noted due to HPV causation becoming a predominant form of the disease in the past 15 years. A favorable outcome for stage III and IV disease challenged existing stage classification (AJCC $7^{\text {th }}$ edition) [6] while lymph node involvement and extent of nodal disease lost its prognostic significance.[7] Surveillance, Epidemiology, and End Results (SEER) 
data [8] showed that the T4 had an appreciably higher HR for survival compared with T1, and reduced HR for survival for all AJCC $7^{\text {th }}$ edition N2 subcategories compared with N0 disease.

Studies from the Princess Margaret Hospital [9] and International Collaboration on Oropharyngeal Cancer Network for Staging (ICON-S) [10] helped derived classifications for the HPV+ cohort [9], which was subsequently adopted by the UICC and AJCC for the eighth edition TNM to more appropriately depict the character and prognosis of the disease.[10]

To summarize accumulated evidence and fastgrowing body of data regarding HPV+ tumors, we undertook an effort to highlight the most important aspects of HPV+ HNC today.

\section{Etiology}

Role of HPV in oral and oropharyngeal carcinogenesis seems to have been first proposed by Syrjanen et al.[11] in 1983 while HPV16 DNA was first detected in invasive SQC HNC of the oral tongue by Southern blot hybridization in 1986.[12] The last two decades have brought increasing evidence which firmly established a connection between HPV infection and the existence of a subgroup of SQC HNC, in particular, oral cavity and oropharynx.[13-23] Gillison et al.[21] used polymerase chain reaction (PCR)-based assays, Southern blot, and in situ hybridization (ISH), to detect HPV DNA in 62 (25\%) of 253 cases with HPV 16 being identified in $90 \%$ of the HPV+ tumors. The HPV+ was detected in $12 \%$ of the oral cavity, $57 \%$ of the oropharynx, $10 \%$ of the hypopharynx, $19 \%$ of the larynx, and $0 \%$ of nasopharynx cases. Correlating HPV status with other factors disclosed that poor tumor grade (odds ratio, $\mathrm{OR}=2.4$ ) and oropharyngeal site $(\mathrm{OR}=6.2)$ independently increased the probability of HPV presence by multivariate analysis (MVA). As compared with HPV- OPC, HPV+ OPC were less likely to occur among moderate to heavy drinkers $(\mathrm{OR}=0.17)$ and smokers $(\mathrm{OR}=0.16)$, had characteristic basaloid morphology $(\mathrm{OR}=18.7)$, and were less likely to have TP53 mutations ( $\mathrm{OR}=0.06)$.

Although it was long ago recognized that histologically HPV+ SQC HNC is poorly differentiated with a basaloid morphology and lack of keratinization [21] the diagnosis cannot be made based exclusively on histologic criteria. Immunohistochemical (IHC) testing and/or HPV DNA/RNA testing are required and are considered the standard of care. p16 IHC is considered useful surrogate for HPV+ HNC in OPC but is rarely used in non-OPC, where HPV+ tumors are rare, leading to a high false-positive rate. Recently, The College of American Pathologists produced an evidence-based guideline on testing, application, interpretation, and reporting of HPV and surrogate marker tests in HNC [24] while subsequently, American Society of Clinical Oncology endorsed it with small modifications. [25] Detailed information is contained in the two documents referenced above.

It is nowadays believed that the high-risk HPV is able to insert specific DNA fragments (early genes E5, E6 and E7) into the cellular genome of its host. Some key functions of tumor suppressor factors are then abrogated (p21, p53 and pRb pathways) after which defects can be detected in apoptosis, DNA repair mechanisms, as well as in the cell cycle regulation, finally leading to cellular immortalization.

Recent years has also brought increasing knowledge about common genetic aberrations in key signaling pathways. Although the mutation rate in HPV+ and HPV- tumors is quantitatively similar [26,27], the specific mutational signatures are distinct. In addition to mutations, structural aberrations, too, are specific for HPV+ tumors [26-30], including a recent study [31] which points at two subtypes of HPV+ tumors based on expression profiling, while preliminary data from immunotherapy treatment with pembrolizumab in $\mathrm{PD}-\mathrm{L} 1+$ cancers indicated possible pathway in future clinical research in this domain.[32]

\section{Epidemiology}

The incidence of tobacco- (and alcohol-) related OPC is decreasing. Contrary to the cancers deemed as HPV, the incidence of HPV+ OPC is rising [33-43], while both incidence and prevalence of HPV- cancers is decreasing, and was mostly observed in tonsillar carcinoma in younger U.S. populations (ages 20-44 years) from 1973 to 2001, while the incidence of SQC carcinoma in all other oral/pharyngeal sites remained constant or decreased [40], a similar finding from Sweden [41], Denmark [42] or Australia.[43] Regional differences exist, too, as many urban centers report new $\mathrm{HNC}$ cases mostly as HPV+ while non-urban centers mostly report on HPV- tumors, partially related to regional differences in tobacco use.

In a systematic review covering the US, Europe and Asia, Kreimer et al.[4] documented HPV+ prevalence in the oropharynx, $35.6 \%$; oral cavity, $23.5 \%$; and larynx, $24.0 \%$. HPV16 was the most common strain in $30.9 \%$ of OPC, followed by oral cavity SQC carcinoma in $16 \%$ and $16.6 \%$ of laryngeal SQC carcinoma. HPV 16 accounted for $86.7 \%$ of all OPC, $68.2 \%$ of all oral cavity SQC carcinoma, and $69.2 \%$ of all laryngeal SQC carcinoma. HPV18 was found in much less percentage of cases. When studied by geographic/continental location, HPV prevalence in OPC was in North America, $47 \%$, and in Europe, $28.2 \%$. Similarly, Termine et 
al.[44] undertook meta-analysis with 62 studies containing a total of 4852 samples. The pooled prevalence of HPV DNA was $34.5 \%$. The pooled prevalence of oral SQC carcinoma was $38.1 \%$, and that of not site-specific SQC carcinoma was $24.1 \%$. Exclusively focusing on the prevalence of HPV in European populations, Abogunin et al.[45] undertook meta-analysis, which showed the prevalence of HPV of any type in patients with $\mathrm{HNC}$ was $40.0 \%$. HPV was highest in tonsillar cancer $(66.4 \%)$ and lowest in pharyngeal (15.3\%) and tongue $(25.7 \%)$ cancers. Contrasting these findings are reports from other world regions. In South African studies, HPV prevalence in oral SQC carcinoma in South African patients was found to be $0-11.9 \%$ patients [46-48] while the same in Sudanese patients was found to be 0\%.[49] Zhu et al.[50] investigated the relationship between oral SQC carcinoma and HPV in a Chinese population. The overall positivity of HPV and HPV 16 were $58.0 \%$ and $47.7 \%$, respectively, both being significantly higher than those found in normal controls $(10.44 \%$ and $7.1 \%$, respectively). The combined odds ratio of oral SQC carcinoma with HPV and HPV16 infection were 12.7 and 9.0, respectively, when compared with normal controls.

Gillison et al.[51] conducted a first populationbased cross-sectional study to concurrently examine the epidemiology of oral HPV infection among men and women aged 14-69 years. Participants $(n=5579)$ provided a 30-second oral rinse and gargle with mouthwash. The overall prevalence of oral HPV infection was $6.9 \%$. The prevalence of high-risk vs low-risk HPV infections was $3.7 \%$ vs $3.1 \%$. The most prevalent type was HPV16 (1.0\%). The prevalence of oral HPV infection among men and women aged 14 to 69 years was $6.9 \%$ and of HPV 16 was $1.0 \%$. Peak prevalence was among individuals aged 30 to 34 years (7.3\%) and 60 to 64 years (11.4\%). Men had a significantly higher prevalence than women for any oral HPV infection (10.1\% vs $3.6 \%, \mathrm{p}<0.001)$. Infection was less common among those without vs those with a history of any sexual contact $(0.9 \%$ vs $7.5 \%, \mathrm{p}<0.001)$ and increased with the number of sexual partners ( $\mathrm{p}<0.001$ for trend) and cigarettes smoked per day ( $\mathrm{p}<0.001$ for trend). Age, sex, number of sexual partners, and the current number of cigarettes smoked per day were independently associated with oral HPV infection in MVA.

An important observation from various studies included a specific history of sexual behavior.[52-61] Schwartz et al.[52] investigated oral cancer risk in relation to sexual history Among males only, oral SCC risk increased with self-reported decreasing age at first intercourse (OR, 3.4), an increasing number of sex partners (OR, 2.3), and a history of genital warts (HR, 2.2).
Similarly, Smith et al.[53] found that in cancer cases, the prevalence of HPV high-risk types was $20 \%$. Risk factors for HPV- high risk included younger age $(<55$ years vs $>55$ years; adjusted $\mathrm{OR}=3.4$ ) and younger-age cases who had more lifetime sex partners (adjusted $\mathrm{OR}=3.8$ ), practiced oral-genital sex (adjusted $\mathrm{OR}=4.3$ ) or oral-anal sex (adjusted OR=19.5). D'Souza et al.[54] investigated whether sexual behaviors that elevated the odds of OPC developing in a case-control study similarly elevated the odds of oral HPV infection developing among controls. Among controls, the odds of infection developing independently increased with increases in the lifetime number of oral $(p=0007$, for trend) or vaginal sex partners $(\mathrm{p}=0.003$, for trend). Among college-aged men, the odds of oral HPV infection developing increased with increases in the number of recent oral sex partners $(\mathrm{p}=0.046$, for trend) or open-mouthed kissing partners $(\mathrm{p}=0.023$, for trend), but not vaginal sex partners. In the study of Widdice et al.[55] on the sexual behavior of 25 heterosexual couples, $68 \%$ of couples had a type-specific anogenital concordance. Receiving finger-anal sex $(\mathrm{p}=0.05)$, sharing towels $(\mathrm{p}=0.04)$, longer time since last intercourse (women: $\mathrm{p}=0.03$, men: $\mathrm{p}=0.02 \mathrm{men}$ ), and men washing their genitals after sex $(\mathrm{p}=0.03)$ were associated with decreased likelihood of concordance. Persistence of incident HPV types in women was associated with HPV in men ( $p=0.002)$. Studies of Heck et al.[56] and Dahlstrom et al.[57] confirmed that OPC and tonsillar cancer were associated with having a history of an increasing number of lifetime sexual partners, lifetime oral/genital sex partners having a history of same-sex sexual contact among men and with an earlier age at sexual debut. The studies of Pickard et al.[59] and Edelstein [60] showed that ever having consumed alcohol (OR, 0.2), >5 lifetime partners, open-mouth kissing (OR, 4.0) or lifetime oral sex (OR, 4.0) were associated with infection [59] and in a multivariate model [60], incident oral HPV infection was associated with recent frequency of performing oral sex (once per week: HR, 3.7), recent anal sex with men (HR, 42.9), current infection with the same HPV type in the genitals (HR, 6.2), and hyponychium (HR, 11.8). Finally, D'Souza et al.[61] focused on oral HPV infection and cancer risk among long-term sexual partners of patients with HPV + OPC to show that oral HPV16 DNA is commonly detected among patients with $\mathrm{HPV}+\mathrm{OPC}$ at diagnosis, but not among their partners. Partners of patients with HPV+ OPC did not seem to have elevated oral HPV infection compared with the general population. While an extensive body of data in the literature identified sexual behavior as significantly contributing factors to HPV infection and occurrence of HPV+ 
HNC, it must, however, be stressed that sexual behavior is still considered as collinear. That said, it remains difficult to distinguish which sexual behaviors are responsible for HPV transmission from genital tract to the mouth, including deep kissing (French kissing), or rimming (oral-anal contact).[14,55,58-60,62]

\section{Prognostic Implications of Hpv Positivity}

For about a quarter of a century, investigators have tried to provide an insight into the influence of HPV positivity in SQC HNC patients. Initial observations and results were confusing $[14,15,20,21,63-67]$ due to the inclusion of HNC of various sites and treatment modalities while reports frequently lacked detailed outcomes. In one of the landmark studies, Gillison et al.[21] documented that when compared with HPV- OPC, HPV+ OPC achieved improved DFS (hazard ratio, HR, 0.26). After adjustment for the presence of lymph node disease (HR, 2.3), heavy alcohol consumption (HR, 2.6), and age $>60$ years $(\mathrm{HR}, 1.4)$ all patients with $\mathrm{HPV}+$ tumors had a 59\% reduction in risk of death from cancer when compared with HPV- HNC patients (HR, 0.41). Chaturvedi et al.[38] used SEER data covering period 1973-2004 on oral SQC carcinoma classified by anatomic site as potentially HPV-related $(n=17.625)$ or HPV-unrelated $(n=28.144)$. When treated with RT, improvements in OS across calendar periods were more pronounced for HPV-related oral SQCs than HPVunrelated oral SQC carcinomas. Using a meta-analytic approach, Ragin and Taioli [68] showed that patients with HPV+ had a lower risk of dying (meta HR: 0.85), and a lower risk of recurrence (meta HR: 0.62) than HPV- patients. Site-specific analyses showed that patients with HPV + OPC had reduced risk of death (meta HR: 0.72) as well as superior DFS (meta HR: 0.51), with no difference, however, in OS between HPV+ and HPV- non-OPC. A similar approach was performed by Dayyani et al.[69], who observed that the difference in OS significantly favored $\mathrm{HPV}+$ tumors ( $\mathrm{HR}, 0.42$; $\mathrm{p}<0.0001)$. The survival benefit was similar in HPV 16 patients $(\mathrm{HR}, 0.41 ; \mathrm{p}<0.0001)$ and was improved even more in OPC (HR, 0.40; $<<0.0001)$.

Recent reports mostly focused on OPC using different outcomes after various treatment modalities had been used, attempting to correlate outcomes with the various patient- and tumor- as well as treatment-related characteristics. To assess the effects of HPV infection on the response of these tumors to RT, Lindel et al.[70] retrospectively evaluated 99 patients who underwent curative RT (median total dose, 74Gy; range, 54-80.5Gy) given in five daily fractions a week for 5-8 weeks. HPV + patients achieved better local control $(p=0.050)$ and a better OS $(p=0.046)$. In the
MVA, HPV + remained associated with a lower risk of local failure (risk ratio, RR, 0.31; $\mathrm{p}=0.048$ ). Fakhry et al.[71] provided an important correlative study included in the original ECOG protocol 2399, which was a phase II trial of radiochemotherapy (RT-CHT) for organ preservation in resectable stage III or IV SQC carcinomas of the larynx or oropharynx. Two cycles of paclitaxel/carboplatin were followed by concurrent radical RT (70 Gy in 35 daily fractions in 7 weeks) and weekly administration of paclitaxel. After induction CHT, there was significantly higher response rate for HPV + tumors: $82 \%$ vs $55 \%, \mathrm{p}=0.01$. The same was observed when response was evaluated after RT-CHT in $85 / 96$ (89\%) patients: $84 \%$ vs $57 \%, p=0.007$. Significant differences remained when the analysis was restricted to OPCs. HPV+ patients also achieved superior OS and PFS at 2 years (OS, 95\% vs 62\%, respectively; PFS, $86 \%$ vs $53 \%$, respectively). When MVA was performed, $\mathrm{HPV}+$ status remained independent prognosticator of improved OS. When MVA were restricted to OPC, patients with HPV + tumors had a $61 \%$ lower risk of death $(\mathrm{HR}=0.39 ; \mathrm{p}=0.06)$ and $\mathrm{a} 62 \%$ lower risk of progression $(\mathrm{HR}=0.38 ; \mathrm{p}=0.09)$ than patients with HPV- tumors.

Ang et al.[72] carried out a retrospective analysis of the association between tumor HPV status and survival among patients with stage III or IV OPC who were enrolled in a phase III trial comparing accelerated fractionation RT with concomitant boost (72 Gy in 42 fractions in six weeks) with standard fractionation RT (70 Gy in 35 fractions over a 7-week period), each combined with $100 \mathrm{mg} / \mathrm{sqm}$ of CDDP (days 1 and 22 in the former and 1,22 and 43 in the latter group). There was no difference in 3-year OS between the two groups $(70.3 \%$ vs $64.3 \%$; $\mathrm{p}=0.18$; HR for death with accelerated fractionation RT, $0.90)$, as there was no difference in the rates of high-grade acute and late toxic events. $\mathrm{HPV}+$ (detected in OPC in $63.8 \%$ patients) achieved better 3-year OS than HPV- (82.4\%, vs 57.1\%; p<0.001), which was confirmed in MVA which showed that they had a $58 \%$ reduction in the risk of death (HR, 0.42).

In another study, O'Sullivan et al.[73] reported on 764 consecutive OPC patients treated with definitive RT approaches (RT alone, 449; RT-CHT, 315). Of 358 (47\%) evaluable cases $77 \%$ were $\mathrm{HPV}+$ (RT alone, 148 ; RT-CHT, 129) and 81 were HPV- (RT alone 59; RTCHT, 22). Standard institutional policy for stage I-II OPC included RT alone, Stage III patients received either RT-CHT or RT alone using altered fractionation regimens, while Stage IV patients underwent RT-CHT, RT alone being reserved for patients unsuitable for $\mathrm{CHT}$ due to various reasons. HPV + achieved better OS ( $81 \%$ vs $44 \%$ ), local control (LC) (93\% vs 76\%), regional control (RC) $(94 \%$ vs $79 \%)$ (all $\mathrm{p}<0.01)$, but similar dis- 
tant control (DC) $(89 \%$ vs $86 \%, \mathrm{p}=0.87)$ compared to HPV-. HPV+ stage IV treated with RT-CHT had better OS ( $89 \%$ vs $70 \%, \mathrm{p}<0.01)$, but similar LC ( $93 \%$ vs $90 \%$, $\mathrm{p}=0.41)$, RC $(94 \%$ vs $90 \%, \mathrm{p}=0.31)$ and $\mathrm{DC}(90 \%$ vs $83 \%, \mathrm{p}=0.22)$ vs RT alone ( $\mathrm{n}=96)$. Both HPV+ treated with RT alone $(\mathrm{n}=37)$ and RT-CHT $(\mathrm{n}=67)$ stage IV minimal smokers had favorable OS $(86 \%$ vs $88 \%$, $\mathrm{p}=0.45)$, LC ( $95 \%$ vs $92 \%, \mathrm{p}=0.52)$, RC ( $97 \%$ vs $93 \%$, $\mathrm{p}=0.22)$, and DC ( $92 \%$ vs $86 \%, \mathrm{p}=0.37)$. RT alone and heavy-smoking were independent predictors for lower OS but not cancer specific survival (CSS).

More recently, Rosenthal et al.[74] undertook a retrospective analysis of the subgroup of p16-evaluable patients from the IMCL-9815 study in which 253 OPC patients with stage III to IV nonmetastatic SQC HNC randomly received either conventional $\mathrm{RT}$, or twice daily RT, or accelerated RT with concomitant boost alone or RT with weekly cetuximab. When treated with $\mathrm{RT}$ alone, LRC, OS, and PFS were improved in p16+ patients when compared with their p16- counterparts (HRs, 0.30, 0.40, and 0.30, respectively). When treated with RT plus cetuximab, the HRs for LRC, OS, and PFS also favored p16+ OPC patients (HRs, 0.12, 0.16, and 0.18 , respectively). RT/cetuximab carried 3-year LRC advantage over RT alone in both p16+ OPC and p16OPC patients (HRs, 0.31 and 0.78 , respectively), as well as it offered superior 3-year OS rate when compared to RT alone in both p16+ OPC, and p16- OPC patients (HR, 0.38 and 0.93 , respectively). Analysis of PFS at 3 -years recapitulated the outcome in OS and LRC. RT/Cetuximab was superior to RT alone in both p16+ OPC and p16- OPC (HRs, 0.46 and 0.76 , respectively). However, despite the numerical advantage, due to a relatively small patient subset, no significant interaction between the treatment group and p16 status could be shown for any of the endpoints. Spreafico et al.[75] evaluated CDDP dose density in both patients with HPV+ and HPV- locally advanced SQC HNC treated with RT-CHT. A pooled analysis included patients with stage III/IV OPC, carcinoma of unknown primary (CUP) and laryngo-hypopharyngeal cancer (LHC) treated with single-agent CDDP CRT from 2000 to 2012. Three-year OS for CDDP $<200$, vs 200 , and $>200$ $\mathrm{mg} / \mathrm{m}^{2}$ subgroups were $52 \%, 60 \%$, and $72 \%(\mathrm{p}=0.001)$ for the HPV- and $91 \%, 90 \%$, and $91 \%(\mathrm{p}=0.30)$ for the HPV+ patients. MVA confirmed a survival benefit with CDDP $>200 \mathrm{mg} / \mathrm{m}^{2}$ for the HPV- (HR, 0.5, $\mathrm{p}<0.001$ ), but not for HPV+ (HR 0.6, $\mathrm{p}=0.104)$. There was a superior OS trend in the HPV+ T4 or N3 high-risk subset patients with CDDP $>200 \mathrm{mg} / \mathrm{m}^{2}(\mathrm{HR}, 0.5, \mathrm{p}=0.07)$.

Several researchers attempted to identify possible subgroups of HPV+ OPC that might request specific (e.g. less intensive) approach due to their inherent characteristics leading to a different (e.g. superior) outcome. In a retrospective analysis of The Radiation Therapy Oncology Group (RTOG) 0129 study, Ang et al.[72] showed the importance of HPV status and called for the separation of future trials addressing these two entities. Using recursive partitioning analysis (RPA), they classified patients' risk of death on the basis of four factors: HPV status, pack-years of tobacco smoking, $\mathrm{T}$ stage, and $\mathrm{N}$ stage. RPA analysis showed that the HPV status of the tumor was the major determinant of OS, followed by the number of pack-years of tobacco smoking ( $\leq 10$ vs $>10$ ) and then nodal stage (N0 to N2a vs N2b to N3), for HPV+ tumors, or tumor stage (T2 or T3 vs T4), for HPV- tumors. Three categories with respect to the risk of death were identified: low risk, with 3 -year OS of $93.0 \%$; intermediate risk, with a 3-year OS of $70.8 \%$ (HR for the comparison with low risk, 3.54); and high risk, with a 3 -year OS of $46.2 \%$ (HR for the comparison with low risk, 7.16). Patients with HPV+ tumors were considered to be at low risk, with the exception of smokers with a high nodal stage (i.e., N2b to N3), who were considered to be at intermediate risk; patients with HPV- tumors were considered to be at high risk, with the exception of non-smokers with tumors of stage T2 or T3, who were considered to be at intermediate risk. One of the implications of their risk model was that low-risk patients could potentially be spared the intensive, multimodal therapy without compromising their survival (yet, reducing rates of serious adverse events). Similarly, beside HPV status, Canadian group [73] reconfirmed $>10$ smoking pack-years (HR, $1.68 ; \mathrm{p}=0.034)$, older age $(\mathrm{HR}, 1.03 ; \mathrm{p}=0.003), \mathrm{T} 4(\mathrm{HR}$, $1.88 ; \mathrm{p}=0.002)$, N2b-N3 (HR, 1.82; $\mathrm{p}=0.004)$, as independent prognostic factors. In their further attempt, O'Sullivan et al.[76] retrospectively analyzed 899 OPC patients treated with RT (mostly accelerated fractionation) or RT-CHT. They have identified a subgroup of $\mathrm{HPV}+\mathrm{OPC}$ patients deemed suitable candidates for de-intensification of treatment approaches based on their minimal risk of distant metastasis (DM). Based on their distinct clinical characteristics leading to different outcome among identified subgroups, RPA segregated $\mathrm{HPV}+$ patients into low (T1-3 N0-2c; distant control (DC), 93\%; locoregional control (LRC), 95\%) and high DM risk (N3 or T4; DC, 76\%) groups and HPV- patients into different low (T1-2N0-2c; DC, 93\%) and high DM risk (T3-4N3; DC, 72\%) groups. The DC rates for HPV+, low-risk N0-2a or less than 10 pack-year N2b patients were similar for RT alone and RT-CHT, but the rate was lower in the N2c subset treated with RT alone $(73 \%$ v $92 \%$ for RT-CHT; $\mathrm{p}=0.02$ ). What these results implicated was that this low DM had been achieved with intensified treatment 
in patients with advanced $\mathrm{N}$ category, especially N2c disease. Among the HPV+ low-risk group, RT alone, using mostly (>90\%) accelerated regimens in the study, was equally effective regarding DC for $\mathrm{N} 0-2 \mathrm{a}$ and $\mathrm{N} 2 \mathrm{~b}$ minimal smokers, and might represent an alternative option for low-risk HPV+ patients, at least for the N02a patients and $\mathrm{N} 2 \mathrm{~b}$ minimal smokers, due to superiority of accelerated RT in the HPV+ patients observed in other studies, too.[12] In the aforementioned study of Spreafico et al.[75], additional effort was undertaken to focus upon HPV+ OPC high mortality risk patients as defined by Ang et al.[67] and consisting of N2b-N3 and $>10$ smoking pack-year. No survival difference was found between CDDP $>200$ and $<200 \mathrm{mg} / \mathrm{m}^{2}$ (3-year: $90 \%$ vs $90 \%, p=0.76)$ with an HR of $0.92(p=0.85)$. In contrast, a non-significant lower mortality risk for CDDP $>200 \mathrm{mg} / \mathrm{m}^{2}$ and $<200 \mathrm{mg} / \mathrm{m}^{2}$ was found for the high DM risk subset (T4 or N3), defined by O'Sullivan et al.[76] (3- year OS: 76\% vs 79\%, $\mathrm{p}=0.15$ ) with the adjusted HR of 0.5 by MVA ( $\mathrm{p}=0.07$ ).

Intensive clinical research [77-89] provided a fruitful milieu for clinical investigators to embark on an exploration of various efforts to optimize treatment approaches by de-intensifying it when and where appropriate. As summarized by Mirghani et al.[77], these efforts can broadly be divided between those substituting CDDP by cetuximab, those aiming de-intensification of RT and $\mathrm{CHT}$, those using induction $\mathrm{CHT}$ followed by lower RT dose, those using upfront surgery as well as those using vaccines. Two past years brought four prospective studies aiming to optimize the treatment approaches in HPV+ OPC using combined RT and CHT. First of the four important and recent studies was a phase II trial of Marur et al.[80] where patients with HPV16 and/or p16+, stage III-IV SQC HNC received three cycles of induction CDDP, paclitaxel and cetuximab. Intensity-modulated RT (IMRT) with 54 Gy was offered concurrently with weekly cetuximab to patients with clinically complete response (cCR) at primary-site. In a risk-adapted approach, patients with less than cCR to induction CHT at the primary site or nodes received $69.3 \mathrm{~Gy}$ and cetuximab weekly. cCR was achieved a primary-site in $70 \%$ while $64 \%$ of patients continued to cetuximab with IMRT 54 Gy. PFS and OS at two years were $80 \%$ and $94 \%$, respectively, for 51 patients with primary-site cCR treated with RT with $54 \mathrm{~Gy}$. For the favorable (low risk) group $(<\mathrm{T} 4$, $<\mathrm{N} 2 \mathrm{c}$, and $<10$ pack-year smoking history) treated with RT <54 Gy (n=27), corresponding figures were $96 \%$ and $96 \%$, respectively. Importantly, significantly fewer patients treated with a RT dose $<54$ Gy had difficulty swallowing solids ( $40 \%$ v $89 \%$; $\mathrm{p}=0.011$ ) or had impaired nutrition ( $10 \% \mathrm{v} 44 \%$; $\mathrm{p}=0.025)$ after 1 -year.
Chen et al.[81] reported on a single-arm, phase 2 trial in $\mathrm{HPV}+$ patients with newly diagnosed stage III or IV SQC OPC, and PS 0 or 1 . Two cycles of induction paclitaxel and carboplatin were followed by IMRT with concurrent paclitaxel weekly. CRs and PRs to induction CHT received 54 Gy in 27 fractions, and those with less than partial or no responses received $60 \mathrm{~Gy}$ in 30 fractions. Twenty-four (55\%) patients received 54 Gy, and 20 (45\%) received 60 Gy. Three (7\%) patients had LRF, and one (2\%) had DM; 2-year PFS was 92\%. 26 (39\%) patients experienced grade 3 adverse events; however, no grade 4 events were reported. The most common grade 3 events during induction CHT were leucopenia (39\%) and neutropenia (11\%), and during RT-CHT were dysphagia (9\%) and mucositis (9\%). Only one (2\%) patient was a gastrostomy tube-dependent at three months, but none of the patients had so six months after treatment. The authors concluded that reducing the RT dose by $15-20 \%$ was associated with excellent results with an improved toxicity profile compared with historical regimens using standard doses.

Remaining two studies were large prospective phase III studies. RTOG 1016 [82] was a randomized, non-inferiority trial which included adult patients with histologically confirmed HPV+ OPC; clinical categories T1-2, N2a-3 M0 or T3-4, N0-3, good performance status (Zubrod 0-1) and adequate bone marrow, hepatic, and renal function. Patients received RT plus either cetuximab or CDDP. Intravenous cetuximab at a loading dose of $400 \mathrm{mg} / \mathrm{m}^{2}$ was administered 5-7 days before the start of RT, followed by cetuximab $250 \mathrm{mg} /$ $\mathrm{m}^{2}$ weekly for seven doses, while CDDP $100 \mathrm{mg} / \mathrm{m}^{2}$ was administered on days 1 and 22 of RT. All patients received accelerated IMRT ( 70 Gy in 35 fractions over 6 weeks). The primary endpoint was OS. RT/cetuximab did not meet the non-inferiority criteria for OS $(\mathrm{HR}$, 1.45 , one-sided $95 \%$ upper CI 1.94; $\mathrm{p}=0.5056$ for noninferiority; one-sided log-rank $\mathrm{p}=0.0163$ ). Estimated 5-year OS for the RT/cetuximab and RT/CDDP were $77.9 \%$ and $84.6 \%$, respectively. PFS was significantly lower in the RT/cetuximab than in RT/CDDP group of patients (HR 1.72, 95\% CI 1.29-2.29; $\mathrm{p}=0.0002$; 5-year PFS $67.3 \%$, vs $78.4 \%$ ), as well as LRF was significantly higher in the RT /cetuximab than in the RT/CDDP group (HR 2.05, 95\% CI 1.35-3.10; 5-year: 17.3\%, vs 9.9\%). There was no difference in rates of either acute moderate to severe toxicity $(77.4 \%$, vs $81.7 \%$; $\mathrm{p}=0.1586)$ or late moderate to severe toxicity $(16.5 \%$, vs $20.4 \%$; $\mathrm{p}=0.1904$ ) between the cetuximab and CDDP groups. Authors concluded that RT plus CDDP should be considered the standard of care for eligible patients with HPV+ OPC. Finally, in the prospective randomized study of Mehanna et al.[89], De-ESCALaTE HPV, ce- 
tuximab was administered to de-escalate the treatment intensity and reduce side effects of standard CDDP administration in a low-risk HPV+ OPC (non-smokers or lifetime smokers with a smoking history of $<10$ pack-years). Patients received conventional RT, with either concurrent CDDP $(100 \mathrm{mg} / \mathrm{sqm}$ on days 1,22 , and 43 of RT) or cetuximab ( $400 \mathrm{mg} / \mathrm{m}^{2}$ loading dose followed by seven weekly infusions of $250 \mathrm{mg} / \mathrm{m}^{2}$ ). The primary outcome was overall severe (grade 3-5) toxicity events at 24 months from the end of treatment. There was no difference in overall (acute and late) severe (grade 3-5) toxicity between treatment groups at two years $(\mathrm{p}=0.98)$ nor in overall all-grade toxicity $(\mathrm{p}=0.49)$. There was, however, significantly superior both OS at two years with CDDP vs cetuximab (97.5\% vs $89.4 \%$; HR, 5.0 [95\% CI 1.7-14.7]; $\mathrm{p}=0.001$ ) and 2-year recurrence rate $(6.0 \%$ vs $16.1 \%$, HR, 3.4 [1.67.2; $\mathrm{p}=0.0007)$. Similar to RTOG 1016 study [82], DeESCALaTE study [89] demonstrated that cetuximab showed no benefit regarding toxicity when compared to standard CDDP, but achieved significantly inferior OS and tumour control, which led study authors to conclude the same as RTOG: RT and CDDP should be used as the standard of care for HPV+ low-risk patients who are able to tolerate CDDP. Another matter of concern was that $<50 \%$ of patients received the full CDDP dose, yet there was still a significant advantage for CDDP over cetuximab although most patients received the full regimen of the latter drug.

\section{Conclusion}

$\mathrm{HPV}+\mathrm{OPC}$ has emerged as the most interesting entity in the HNC in the past several decades. Increasing incidence with favorable prognosis seems to have driven clinical research in this field around the world. De-intensification of treatment approaches is seen as a major effort of institutions and collaborative groups. In addition to it, further research needs to be conducted to further increase our knowledge about possible predictive and prognostic factors in this setting.

\section{Peer-review: Externally peer-reviewed.}

Conflict of Interest: Authors declare no conflict of interest.

Financial Support: This work was partially funded by the grants from the Serbian Ministry of Education, Science and Technological Development III41007, ON174028.

\section{References}

1. Jemal A, Siegel R, Ward E, Murray T, Xu J, Thun MJ. Cancer statistics, 2007. CA Cancer J Clin; 57(1):43-66.
2. Jemal A, Bray F, Center MM, Ferlay J, Ward E, Forman D. Global cancer statistics. CA Cancer J Clin 2011; 61(2):69-90.

3. Siegel RL, Miller KD, Jemal A. Cancer statistics, 2015. CA Cancer J Clin. 2015; 65(1):5-29.

4. Kreimer, A, Clifford G, Boyle P, Franceschi S. Human papillomavirus types in head and neck squamous cell carcinomas worldwide: A systematic review. Cancer Epidemiol Biomarkers Prev 2005, 14(2):467-75.

5. World Health Organization. IARC Monographs on the Evaluation of Carcinogenic Risks to Humans - Monograph 90. Lyon, France: International Agency for Research on Cancer; 2007.

6. Dahlstrom KR, Calzada G, Hanby JD, Garden AS, Glisson BS, Li G,et al. An evolution in demographics, treatment, and outcomes of oropharyngeal cancer at a major cancer center: a staging system in need of repair. Cancer. 2013;119(1): 81-9.

7. Straetmans JM, Olthof N, Mooren JJ, de Jong J, Speel EJ, Kremer B. Human papillomavirus reduces the prognostic value of nodal involvement in tonsillar squamous cell carcinomas. Laryngoscope. 2009; 119(10):1951-7.

8. Keane FK, Chen YH, Neville BA, Tishler RB, Schoenfeld JD, Catalano PJ et al. Changing prognostic significance of tumor stage and nodal stage in patients with squamous cell carcinoma of the oropharynx in the human papillomavirus era. Cancer. 2015; 121(15): 2594-602.

9. Huang SH, Xu W, Waldron J, Siu L, Shen X, Tong L, et al. Refining American Joint Committee on Cancer/ Union for International Cancer Control TNM stage and prognostic groups for human papillomavirus-related oropharyngeal carcinomas. J Clin Oncol. 2015; 33 (8):836-45.

10. O'Sullivan B, Huang SH, Su J, Garden AS, Sturgis EM, Dahlstrom K, et al. Development and validation of a staging system for HPV-related oropharyngeal cancer by the International Collaboration on Oropharyngeal cancer Network for Staging (ICON-S): a multicentre cohort study. Lancet Oncol. 2016;17(4):440-51

11. Syrjänen K, Syrjänen S, Lamberg M, Pyrhönen S, Nuutinen J. Morphological and immunohistochemical evidence suggesting human papillomavirus (HPV) involvement in oral squamous cell carcinogenesis. Int J Oral Surg. 1983;12(6):418-24.

12. de Villiers EM, Neumann C, Le JY, Weidauer H, zur Hausen $\mathrm{H}$. Infection of the oral mucosa with defined types of human papillomaviruses. Med Microbiol Immunol. 1986; 174(6):287-94.

13. Niedobitek G, Pitteroff S, Herbst H, Shepherd P, Finn T, Anagnostopoulos I, et al. Detection of human papil- 
lomavirus type 16 DNA in carcinomas of the palatine tonsil. J Clin Pathol. 1990; 43(11):918-21.

14. Snijders PJ, Cromme FV, van den Brule AJ, Schrijnemakers HF, Snow GB, Meijer CJ, et al. Prevalence and expression of human papillomavirus in tonsillar carcinomas, indicating a possible viral etiology. Int $\mathrm{J}$ Cancer. 1992; 51(6):845-50.

15. Haraf DJ, Nodzenski E, Brachman D, Mick R, Montag A, Graves D, et al. Human papilloma virus and p53 in head and neck cancer: clinical correlates and survival. Clin Cancer Res.1996; 2(4):755-62.

16. Steinberg BM, DiLorenzo TP. A possible role for human papillomaviruses in head and neck cancer.Cancer Metastasis Rev. 1996; 15(1):91-112.

17. Paz IB, Cook N, Odom-Maryon T, Xie Y, Wilczynski SP. Human papillomavirus (HPV) in head and neck cancer. An association of HPV 16 with squamous cell carcinoma of Waldeyer's tonsillar ring. Cancer. 1997; 79(3):595-604.

18. McKaig RG, Baric RS, Olshan AF. Human papillomavirus and head and neck cancer: epidemiology and molecular biology. Head Neck. 1998; 20(3):250-65.

19. Wilczynski SP, Lin BT, Xie Y, Paz IB. Detection of human papillomavirus DNA and oncoprotein overexpression are associated with distinct morphological patterns of tonsillar squamous cell carcinoma. Am J Pathol. 1998; 152(1):145-56.

20. Andl T, Kahn T, Pfuhl A, Nicola T, Erber R, Conradt $\mathrm{C}$, et al. Etiological involvement of oncogenic human papillomavirus in tonsillar squamous cell carcinomas lacking retinoblastoma cell cycle control.Cancer Res. 1998; 58(1):5-13.

21. Gillison ML, Koch WM, Capone RB, Spafford M, Westra $\mathrm{WH}, \mathrm{Wu} \mathrm{L}$, et al. Evidence for a causal association between human papillomavirus and a subset of head and neck cancers. J Natl Cancer Inst. 2000; 92(9):709-20.

22. Ragin CC, Taioli E, Weissfeld JL, White JS, Rossie KM, Modugno F, et al. 11q13 amplification status and human papillomavirus in relation to p16 expression defines two distinct etiologies of head and neck tumours. Br J Cancer. 2006; 95(10):1432-8.

23. D’Souza G, Kreimer AR, Viscidi R, Pawlita M, Fakhry C, Koch WM, et al. Case-control study of human papillomavirus and oropharyngeal cancer. N Engl J Med. 2007; 356(19):1944-56.

24. Lewis JS Jr, Beadle B, Bishop JA, Chernock RD, Colasacco C, Lacchetti C, et al. Human Papillomavirus Testing in Head and Neck Carcinomas: Guideline From the College of American Pathologists. Arch Pathol Lab Med. 2018; 142(5):559-97

25. Fakhry C, Lacchetti C, Rooper LM, Jordan RC, Rischin D, Sturgis EM, et al. Human Papillomavirus
Testing in Head and Neck Carcinomas: ASCO Clinical Practice Guideline Endorsement of the College of American Pathologists Guideline. J Clin Oncol. 2018; 36(31):3152-61

26 Cancer Genome Atlas N. Comprehensive genomic characterization of head and neck squamous cell carcinomas. Nature. 2015; 517(7536):576-82.

27. Seiwert TY, Zuo Z, Keck MK, Khattri A, Pedamallu $\mathrm{CS}$, Stricker $\mathrm{T}$, et al. Integrative and comparative genomic analysis of HPV-positive and HPV-negative head and neck squamous cell carcinomas. Clin Cancer Res. 2015; 21(3):632-41.

28. Smeets SJ, Braakhuis BJ, Abbas S, Snijders PJ, Ylstra B, van de Wiel MA, et al. Genome-wide DNA copy number alterations in head and neck squamous cell carcinomas with or without oncogene- expressing human papillomavirus. Oncogene. 2006; 25(17):2558-64.

29. Hayes DN, Van Waes C, Seiwert TY. Genetic Landscape of Human Papillomavirus- Associated Head and Neck Cancer and Comparison to Tobacco- Related Tumors. J Clin Oncol. 2015; 33(29):3227-34.

30. Rischin D, Young RJ, Fisher R, Fox SB, Le QT, Peters LJ, et al. Prognostic significance of p16INK4A and human papillomavirus in patients with oropharyngeal cancer treated on TROG 02.02 phase III trial. J Clin Oncol. 2010; 28(27):4142-48.

31. Keck MK, Zuo Z, Khattri A, Stricker TP, Brown CD, Imanguli $\mathrm{M}$, et al. Integrative analysis of head and neck cancer identifies two biologically distinct HPV and three non-HPV subtypes. Clin Cancer Res. 2015; 21(4):870-81.

32. Seiwert T, Burtness B, Weiss J, Eder JP,r, Yearley J, Murphy E, et al. Inflamed-phenotype gene expression signatures to predict benefit from the anti-PD-1 antibody pembrolizumab in PD-L1+ head and neck cancer patients. J Clin Oncol. 2015; 33(suppl):abstr 6017.

33. Pytynia KB, Dahlstrom KR, Sturgis EM. Epidemiology of HPV-associated oropharyngeal cancer. Oral Oncol. 2014; 50(5): 380-6.

34. Junor E, Kerr G, Oniscu A, Campbell S, Kouzeli I, Gourley C, et al. Benefit of chemotherapy as part of treatment for HPV DNA-positive but P16-negative squamous cell carcinoma of the oropharynx. Br. J. Cancer 2012; 106(2):358-65.

35. Ernster JA, Sciotto CG, O'Brien MM, Finch JL, Robinson LJ, Willson T, et al. Rising incidence of oropharyngeal cancer and the role of oncogenic human papilloma virus. Laryngoscope. 2007; 117(12):2115-28.

36. Licitra L, Perrone F, Bossi P, et al. High-risk human papillomavirus affects prognosis in patients with surgically treated oropharyngeal squamous cell carcinoma. J Clin Oncol. 2006; 24(36):5630-6. 
37. Weinberger PM, Yu Z, Haffty BG, Kowalski D, Harigopal M, Brandsma J, et al. Molecular classification identifies a subset of human papillomavirus--associated oropharyngeal cancers with favorable prognosis. J Clin Oncol. 2006; 24(5):736-47

38. Chaturvedi AK, Engels EA, Anderson WF, Gillison ML. Incidence trends for human papillomavirus-related and -unrelated oral squamous cell carcinomas in the United States. J Clin Oncol. 2008; 26(4):612-9

39. Sturgis EM, Cinciripini PM. Trends in head and neck cancer incidence in relation to smoking prevalence: an emerging epidemic of human papillomavirus-associated cancers? Cancer. 2007; 110(7):1429-35.

40. Shiboski CH, Schmidt BL, Jordan RC. Tongue and tonsil carcinoma: increasing trends in the U.S. population ages 20-44 years.Cancer. 2005; 103(9):1843-9.

41. Hammarstedt L, Lindquist D, Dahlstrand H, Romani$\tan$ M, Dahlgren LO, Joneberg J, et al. Human papillomavirus as a risk factor for the increase in incidence of tonsillar cancer. Int J Cancer. 2006; 119(11):2620-3.

42. Lassen P, Eriksen JG, Hamilton-Dutoit S, Tramm T, Alsner J, Overgaard J.Effect of HPV-associated p16INK4A expression on response to radiotherapy and survival in squamous cell carcinoma of the head and neck. J Clin Oncol. 2009; 27(12):1992-8.

43. Hocking JS, Stein A, Conway EL, Regan D, Grulich A, Law M, et al. Head and neck cancer in Australia between 1982 and 2005 show increasing incidence of potentially $\mathrm{HPV}$-associated oropharyngeal cancers. $\mathrm{Br}$ J Cancer. 2011; 104(5):886-91

44. Termine N, Panzarella V, Falaschini S, Russo A, Matranga D, Lo Muzio L, et al. HPV in oral squamous cell carcinoma vs head and neck squamous cell carcinoma biopsies: a meta-analysis (1988-2007). Ann Oncol. 2008; 19(10):1681-90.

45. Abogunrin S, Di Tanna GL, Keeping S, Carroll S, Iheanacho I. Prevalence of human papillomavirus in head and neck cancers in European populations: a meta-analysis.BMC Cancer. 2014; 14:968.

46. Van Rensburg EJ, van Heerden WF, Venter EH, Raubenheimer EJ. Detection of human papillomavirus DNA with in situ hybridisation in oral squamous carcinoma in a rural black population. S Afr Med J. 1995; 85(9):894-6.

47. Van Rensburg EJ, Engelbrecht S, Van Heerden WF, Raubennheimer EJ, Schoub BD. Human papillomavirus DNA in oral squamous cell carcinomas from an African population sample. Anticancer Res. 1996; 16(2):969-73.

48. Boy S, Van Rensburg EJ, Engelbrecht S, Dreyer L, van Heerden M, van Heerden W.HPV detection in primary intra-oral squamous cell carcinomas--commen- sal, aetiological agent or contamination? J Oral Pathol Med. 2006; 35(2):86-90

49. Ibrahim SO, Bertelsen B, Kalvenes MB, Idris AM, Vasstrand EN, Nilsen R, et al. Expression of keratin 13, 14 and 19 in oral squamous cell carcinomas from Sudanese snuff dippers: lack of association with human papillomavirus infection.APMIS. 1998; 106(10):959-69.

50.Zhu C, Ling Y, Dong C, Zhou X, Wang F.The relationship between oral squamous cell carcinoma and human papillomavirus: a meta-analysis of a Chinese population (1994-2011). PLoS One. 2012; 7(5):e36294

51. Gillison ML, Broutian T, Pickard RK, Tong ZY, Xiao W, Kahle L, et al. Prevalence of oral HPV infection in the United States, 2009-2010.JAMA. 2012; 307(7):693-703.

52. Schwartz SM, Daling JR, Doody DR, Wipf GC, Carter $\mathrm{JJ}$, Madeleine MM, et al.Oral cancer risk in relation to sexual history and evidence of human papillomavirus infection.J Natl Cancer Inst. 1998; 90(21):1626-36.

53. Smith EM, Ritchie JM, Summersgill KF, Klussmann JP, Lee JH, Wang D, et al.Age, sexual behavior and human papillomavirus infection in oral cavity and oropharyngeal cancers. Int J Cancer. 2004; 108(5):766-72.

54. D’Souza G, Agrawal Y, Halpern J, Bodison S, Gillison ML. Oral sexual behaviors associated with prevalent oral human papillomavirus infection. J Infect Dis. 2009; 199(9):1263-9.

55. Widdice LE, Breland DJ, Jonte J, Farhat S, Ma Y, Leonard AC, et al.Human papillomavirus concordance in heterosexual couples. J Adolesc Health. 2010; 47(2):151-9.

56. Heck JE, Berthiller J, Vaccarella S, Winn DM, Smith EM, Shan'gina O, et al. Sexual behaviours and the risk of head and neck cancers: a pooled analysis in the International Head and Neck Cancer Epidemiology (INHANCE) consortium. Int J Epidemiol. 2010; 39(1):166-81.

57. Dahlstrom KR, Li G, Tortolero-Luna G, Wei Q, Sturgis EM.Differences in history of sexual behavior between patients with oropharyngeal squamous cell carcinoma and patients with squamous cell carcinoma at other head and neck sites.Head Neck. 2011; 33(6):847-55.

58. Kreimer AR, Villa A, Nyitray AG, Abrahamsen M, Papenfuss M, Smith D, et al. The epidemiology of oral HPV infection among a multinational sample of healthy men. Cancer Epidemiol Biomarkers Prev. 2011; 20(1):172-82.

59. Pickard RK, Xiao W, Broutian TR, He X, GillisonML. The prevalence and incidence of oral human papillomavirus infection among young men and women, aged 18-30 years. Sex Transm Dis. 2012; 39(7):559-66.

60. Edelstein ZR, Schwartz SM, Hawes S, Hughes JP, Feng $\mathrm{Q}$, Stern ME, et al. Rates and determinants of oral 
human papillomavirus infection in young men. Sex Transm Dis. 2012; 39(11):860-7.

61. D'Souza G, Gross ND, Pai SI, Haddad R, Anderson KS, Rajan S, et al. Oral human papillomavirus (HPV) infection in HPV-positive patients with oropharyngeal cancer and their partners. J Clin Oncol. 2014; 32(23):2408-15.

62. Kreimer AR, Alberg AJ, Daniel R, Gravitt PE, Viscidi $\mathrm{R}$, Garrett ES, et al.Oral human papillomavirus infection in adults is associated with sexual behavior and HIV serostatus. J Infect Dis. 2004; 189(4):686-98

63. Pintos J, Black MJ, Sadeghi N, Ghadirian P, Zeitouni AG, Viscidi RP, et al.Human papillomavirus infection and oral cancer: a case-control study in Montreal, Canada. Oral Oncol. 2008; 44(3):242-50.

64. Riethdorf S, Friedrich RE, Ostwald C, Barten M, Gogacz P, Gundlach KK, et al. p53 gene mutations and HPV infection in primary head and neck squamous cell carcinomas do not correlate with overall survival: a long-term follow-up study. J Oral Pathol Med. 1997; 26(7):315-21.

65. Chiba I, Shindoh M, Yasuda M, Yamazaki Y, Amemiya A, Sato Y, et al.Mutations in the p53 gene and human papillomavirus infection as significant prognostic factors in squamous cell carcinomas of the oral cavity. Oncogene. 1996; 12(8):1663-8.

66. Portugal LG, Goldenberg JD, Wenig BL, Ferrer KT, Nodzenski E, Sabnani JB, et al. Human papillomavirus expression and $\mathrm{p} 53$ gene mutations in squamous cell carcinoma. Arch Otolaryngol Head Neck Surg. 1997; 123(11):1230-4.

67. Mellin H, Friesland S, Lewensohn R, Dalianis T, Munck-Wikland E. Human papillomavirus (HPV) DNA in tonsillar cancer: clinical correlates, risk of relapse, and survival. Int J Cancer. 2000; 89(3):300-4.

68. Ragin CC, Taioli E. Survival of squamous cell carcinoma of the head and neck in relation to human papillomavirus infection: review and meta-analysis. Int J Cancer. 2007; 121(8):1813-20.

69. Dayyani F, Etzel CJ, Liu M, Ho CH, Lippman SM, Tsao AS. Meta-analysis of the impact of human papillomavirus (HPV) on cancer risk and overall survival in head and neck squamous cell carcinomas (HNSCC). Head Neck Oncol. 2010; 2:15.

70. Lindel K, Beer KT, Laissue J, Greiner RH, Aebersold DM. Human papillomavirus positive squamous cell carcinoma of the oropharynx: a radiosensitive subgroup of head and neck carcinoma.Cancer. 2001; 92(4):805-13.

71. Fakhry C, Westra WH, Li S, Cmelak A, Ridge JA, Pinto $\mathrm{H}$, et al. Improved survival of patients with human papillomavirus-positive head and neck squamous cell carcinoma in a prospective clinical trial.J Natl Cancer Inst. 2008; 100(4):261-9.

72. Ang KK, Harris J, Wheeler R, Weber R, Rosenthal DI, Nguyen-Tân PF, et al.Human papillomavirus and survival of patients with oropharyngeal cancer. N Engl J Med. 2010; 363(1):24-35

73. O'Sullivan B, Huang SH, Perez-Ordonez B, Massey C, Siu LL, Weinreb I, et al. Outcomes of HPV-related oropharyngeal cancer patients treated by radiotherapy alone using altered fractionation. Radiother Oncol. 2012; 103(1):49-56.

74. Rosenthal DI, Harari PM, Giralt J, Bell D, Raben D, Liu J, et al. Association of Human Papillomavirus and p16 Status With Outcomes in the IMCL-9815 Phase III Registration Trial for Patients With Locoregionally Advanced Oropharyngeal Squamous Cell Carcinoma of the Head and Neck Treated With Radiotherapy With or Without Cetuximab. JClinOncol. 2016; 34(12):1300-8.

75. Spreafico A, Huang SH, Xu W, Granata R, Liu CS, Waldron JN, et al. Impact of cisplatin dose intensity on human papillomavirus-related and -unrelated locally advanced head and neck squamous cell carcinoma. Eur J Cancer. 2016; 67:174-82.

76. O’Sullivan B, Huang SH, Siu LL, Waldron J, Zhao H, Perez-Ordonez B, et al. Deintensification candidate subgroups in human papillomavirus-related oropharyngeal cancer according to minimal risk of distant metastasis. J Clin Oncol. 2013; 31(5):543-50.

77. Mirghani H, Amen F, Blanchard P, Moreau F, Guigay J, Hartl DM, et al. Treatment de-escalation in HPVpositive oropharyngeal carcinoma: ongoing trials, critical issues and perspectives. Int J Cancer. 2015; 136(7):1494-503.

78. Huang J, Zhang J, Shi C, Liu L, Wei Y. Survival, recurrence and toxicity of HNSCC in comparison of a radiotherapy combination with cisplatin versus cetuximab: a meta-analysis. BMC Cancer 2016; 16: 689.

79. Siu LL, Waldron JN, Chen BE, Winquist E, Wright JR, Nabid A et al. Effect of standard radiotherapy with cisplatin vs accelerated radiotherapy with panitumumab in locoregionally advanced squamous cell head and neck carcinoma: a randomized clinical trial. JAMA Oncol 2016; 3(2): 220-6.

80. Marur S, Li S, Cmelak AJ, Gillison ML, Zhao WJ, Ferris RL, et al. E1308: Phase II Trial of Induction Chemotherapy Followed by Reduced-Dose Radiation and Weekly Cetuximab in Patients With HPV-Associated Resectable Squamous Cell Carcinoma of the Oropharynx- ECOG-ACRIN Cancer Research Group. J Clin Oncol. 2017; 35(5):490-7.

81. Chen AM, Felix C, Wang PC, Hsu S, Basehart V, Garst $\mathrm{J}$, et al. Reduced-dose radiotherapy for human papil- 
lomavirus-associated squamous-cell carcinoma of the oropharynx: a single-arm, phase 2 study. Lancet Oncol. 2017; 18(6):803-11.

82. Gillison ML, Trotti AM, Harris J, Eisbruch A, Harari PM, Adelstein DJ, et al. Radiotherapy plus cetuximab or cisplatin in human papillomavirus-positive oropharyngeal cancer (NRG Oncology RTOG 1016): a randomised, multicentre, non-inferiority trial. Lancet. 2019; 393(10166):40-50.

83. Bonner JA, Harari PM, Giralt J, Azarnia N, Shin DM, Cohen RB, et al. Radiotherapy plus cetuximab for squamous-cell carcinoma of the head and neck. $\mathrm{N}$ Engl J Med. 2006; 354(6):567-78.

84. Riaz N, Sherman E, Koutcher L, Shapiro L, Katabi N, Zhang Z, et al. Concurrent chemoradiotherapy with cisplatin versus cetuximab for squamous cell carcinoma of the head and neck. Am J Clin Oncol 2016; 39(1): 27-31

85. Tang C, Chan C, Jiang W, Murphy JD, von Eyben R, Colevas $\mathrm{AD}$, et al. Concurrent cetuximab versus platinum-based chemoradiation for the definitive treatment of locoregionally advanced head and neck cancer. Head Neck 2015; 37(3): 386-92.
86. Barney CL, Walston S, Zamora P, Healy EH, Nolan N, Diavolitsis VM, et al. Clinical outcomes and prognostic factors in cisplatin versus cetuximab chemoradiation for locally advanced p16 positive oropharyngeal carcinoma. Oral Oncol 2018; 79: 9-14.

87. Giralt J, Trigo J, Nuyts S, Ozsahin M, Skladowski K, Hatoum G, et al. Panitumumab plus radiotherapy versus chemoradiotherapy in patients with unresected, locally advanced squamous-cell carcinoma of the head and neck (CONCERT-2): a randomised, controlled, open-label phase 2 trial. Lancet Oncol 2015; 16(2): 221-32.

88. Magrini SM, Buglione M, Corvò R, Pirtoli L, Paiar F, Ponticelli $\mathrm{P}$, et al. Cetuximab and radiotherapy versus cisplatin and radiotherapy for locally advanced head and neck cancer: a randomized phase II trial. J Clin Oncol 2016; 34(5): 427-35

89. Mehanna H, Robinson M, Hartley A, Kong A, Foran B, Fulton-Lieuw T, et al. De-ESCALaTE HPV Trial Group. Radiotherapy plus cisplatin or cetuximab in low-risk human papillomavirus-positive oropharyngeal cancer (De-ESCALaTE HPV): an open-label randomised controlled phase 3 trial.Lancet. 2019; 3 93(10166): 51-60. 